the latter hypothesis as the conclusion most in accord with available evidence, it seems reasonable to suppose that these changes represent an attempt on the part of the parathyroids to supply the deficiency of colloid left by the atrophy of the thyroid itself. The increase of connective tissue, though not excessive, was considerably more marked than I have seen in any other human gland or, with one exception, ${ }^{2}$ in the parathyroid of any mammal or bird. Although five of the six parathyroids were directly continuous with the fibrous capsule of the thyroid, this factor alone will not account for the alterations in the former, because the sixth parathyroid, which lay inferior to the main gland, was quite as affected as its fellows. I look on the increase of fibrous material as pathological, in which case it must be regarded as an early stage of the fibrosis, which had reached so advanced a condition in the thyroid.

In brief, these changes show that the paratbyroids have been stimulated to supply in part the want of colloid, but that at the time of death they were being overtaken by the same fibroid degeneration as had destroyed the thyroid.

Harley-street, W.

\section{PYLORIC STENOSIS AND THE CONDITION OF THE PYLORUS DURING LIFE.}

By C. W. MANSELL MOULliN, M.D. Oxon., F.R.C.S. ENG.,

SEAIOR SURGEON AND LECTURER ON SURGERY AT TIE LONDON HOSPITAL.

NON-MALIGNANT stricture of the pylorus may be caused by the contraction of a scar left by an ulcer that has healed or it may arise independently, without any evidence of ulceration or inflammation, from what appears to be fibroid degeneration of the circular muscle that surrounds it. With the former of these I am not concerned at present. The latter, however, I have met with so often of late that unless I have happened to have come across one of those exceptional series of cases which sometimes occur to everyone I cannot help thinking that it is much more common, and therefore more important, than is usually believed.

Before proceeding further, however, it is necessary to define what constitutes a stricture of the pylorus and to form some idea as to what may be the real size and the distensibility of the opening during life. With this object in view, for some time past whenever I have had occasion to open the abdomen for the purpose of operating upon the stomach $I$ have made it a practice to examine the pylorus as thoroughly as I could. The description in the ordinary textbooks is no doubt accurate, so far as it goes, but it is founded on the extmination of cases after death and it is reasonable to think that the condition post mortem, no matter how soon the examination is made, is not the same that it is during life. The circumstances are not the same. Not only have the changes that set in post mortem to be taken into consideration but there is the loss of the tonic contraction which is present during life and which does not entirely disappear from involuntary muscles, even when the reflexes are abolished. All cases in which there was obvious disease, such as ulceration or a cicatrix or malignant growth, either at the pylorus or close to it, were placed upon one side and only those recorded in which the pylorus appeared to present no gross change. The patients were under complete anæsthesia, with the voluntary muscles of the abdomen relaxed, and the stomach had been emptied in all of them.

The method adopted was naturally not a very elaborate one. The pylorus in each case was carefully felt from the outside to ascertain if there was any hardness or irregularity, and then while it was fixed with the left hand the index finger of the right was made to invaginate the wall of the stomach some way off and was pressed against, or where it was possible without using undue force pushed into, the pylorus. In this way a rough idea could be formed of the size of the opening (under these conditions) and the degree of resistance which it presented. In those cases in which the stomach was opened the examination was afterwards completed with the finger in the interior.

Under ordinary conditions the site of the pylorus is marked by a narrow transrerse groove, slightly paler in colour than the rest. The pylorus itself is firm, almost hard to the touch, the line of transition being more sharply marked on the intestinal side than on that of the stomach When grasped between the finger and thumb it often gives the sensztion of bing nodular and irregular even when there is no disease. This is probably due to irregular muscular contraction, perhaps caused by exposure or by the examination, for it is much less distinct when the finger is passed into the opening. From the interior of the stomach the pylorus feels like a round opening with well-defined edges which just admits the tip of the forefinger. So long as it is normal it yields readily to pressure and there is no difficulty in making the finger, with the wall of the stomach covering it, enter sufficiently far to make sure that the opening is free and soft.

Leaving on one side all cases in which there was some gross lesion, I. found that the size of the pylorus varied from that of a channel which could easily admit three fingers with the invaginated wall of the stomach around them to that of a tiny orifice which could scarcely be felt. The former was in a patient who was suffering from general enteroptosis. Probably this extreme dilatation was due to the same causes which produced the enteroptosis. The pylorus was so indefinite that it was diffeult to find. The sphincter could scarcely be felt, and the stomach and intestine seemed to form one continuous canal without a break. The latter was undoubtedly a case of stenosis, as the muscular coat of the stomach was in a state of hypertrophy, and the stomach during life had been seen and felt to contract through the abdominal wall; but there was no evidence of any scar, an 1 the pylorus, when felt from the outside, did not present any marked degree of irregularity. Between these two I have met with every grade.

The degree of distensibility was no less variable. Normally the muscular tone of the pylorus yields at once to gentle pressure. But in many of these, even in those in which the orifice was not exceptionally small, the pylorus was so hard and rigid that though it might have been torn it would not stretch. When examined from the serous surface there was nothing obviously wrong. The pylorus appeared to be firm, but it was uniform and not particularly enlarged or con. tracted. On trying, however, to press the finger into it, it resisted in such a fashion as to leave no doubt that, though there was no evidence of a scar or old ulcer, it was the seat of fibrous stricture.

I have recently met with no less than seven cases, all with a strong family resemblance to each other, in which the hardness and rigidity of the opening were such as to merit the title of stricture and in which there was no sign of a scar. The size varied. In one the opening could not be felt at all. On inspection from the interior it was so small that it would scarcely admit a probe. In the others the diameter appeared to range from an eighth to a quarter of an inch, but in all alike it was absolutely rigid. When the finger was pressed against it, it was a circular opening in a tense membrane and it would not yield to any reasonable degree of force. There were no adhesions, nor was there any thickening of the peritoneal covering or any other evidence of inflammation or ulceration. It simply seemed as if the circular muscular fibre had disappeared and had been replaced by tough and unyielding fibrous tissue. In one, in which the opening was very small, the walls of the stomach were considerably thickened and the size of the organ appeared to be about the normal. In the others the stomach was distinctly enlarged and the wal is did not appear to be materially changed. I do not attach much importance to this, however, as it is very difficult to judge of the thickness of the walls, and it is not unreasonable to tbink that both the size of the stomach and the apparent thickness of its walls may be considerably influenced by the condition of the patient and of the stomach immediately before the administration of the anresthetic.

Six of these patients were women; one was a man. All had been sent to me with the diagnosis of suspected gastric ulcer. In each the chief symptom had been epigastric pain, more or less griping in character, coming on some time after food was taken, not immediately, and continuing for hours with varying severity. It was due, no doubt, to stomachic colic, as in one or two the contraction of the stomach could be seen or felt to coincide with the waves of pain. Emptying the stomach always gave relief, but vomiting was not an early or a prominent symptom unless the patient induced it voluntarily. Superficial tenderness was present in all in the upper epigastric region. Deep tenderness was either absent or very ill defined. In five there had never been 
hæmatemesis. In the other two there had been some, but it had not been a prominent feature. It had only appeared late in the course of the complaint and was not serious in quantity. I looked upon it rather as a consequence of the vomiting. Melæna had not been noted. The onset in all had been very gradual. It was not possible to fix even an approximate date for the beginning. There was a history of long-continued dyspepsia and there were no symptoms sufficiently defined to mark the transition from simple indigestion to a severe degree of pyloric stenosis. In all there was the suspicion of gastric ulcer and at the operation no trace of ulceration or of the cicatrix left by an ulcer could be found either on the serous or the mucous surface.

Whatever may be the pathology of this affection, it is clear that the muscular fibre of the pylorus has disappeared to a great extent and been replaced by tough and unyielding fibrous tissue. The serous coat is not involved and there is no evidence of inflammation. There may have been a stage of muscular hypertrophy preceding this, but there was nothing to suggest it in any of my cases. The most probable explanation is that the fibrous degeneration is the outcome of long.continued spasmodic contraction, caused by persistent dyspepsia. In the earlier period if the cause is removed before the degeneration has advanced too far cure may be possible without operation. These are probably the cases in which systematic lavage succeeds. But when that stage is reached in which the pylorus is so rigid that it does not yield to any reasonable degree of force spontaneous recovery is most unlikely. Fortunately gastro-enterostomy, especially that modification described by Finney, can be relied upon to effect a permanent cure with the minimum of risk. I performed it in all of these with the very best result. The pain disappeared. The patients improved in weight and strength, and so long as they took reasonable care they were enabled to lead their ordinary lives and live on ordinary diet.

The question of the time for surgical treatment, therefore, turns upon the stage the fibroid degeneration has reached Up to a certain point, if the cause that maintains the spasmodic contraction is removed, absorption may take place and the opening regain its elasticity. Beyond that point, whether the cause is removed or not, absorption can do nothing unless it is assisted in some way. The contraction merely becomes tighter. Unhappily the change is so insidious that, as in all my cases, no definile date could be assigned. But it may be taken as fairly certain, if a case is watched for any length of time, that if the dyspepsia returns again and again after apparent cure, and the stomach shows signs of increasing size, especially if at the same time there is evidence that the muscular coat is capable of work, there must be some form of pyloric obstruction and if this does not soon yield to lavage it is better that the patient should have gastro-enterostomy performed than that he should be allowed to continue in a state of constant pain, steadily deteriorating in health and strength.

There is one caution that must be observed. Gastroenterostomy effects such marvellous results in these cases, that patients, unless they are warned beforehand, are liable to expect too much from it. They are apt to think that they can do what they like and eat what they like, as they did before the operation, forgetting the consequences that followed. It is essential that they should understand what gastro-enterostomy is and what it is intended to do. So far as the difficulty is a mechanical one, to be treated by mechanical means, gastro-enterostomy can be relied upon to effect a cure. It does not treat, or pretend to treat, the condition which preceded the stenosis, and which may continue after the stenosis has been divided. There will not be so much pain, it is true. Such acute attacks of stomachic colic are no longer possible after the contracted sphincter has been divided, and this is one of the great advantages of Finney's method over otbers. But if the conditions of living which gave rise to the dyspepsia at the first, when the stomach was still perfectly healthy, are allowed to continue, they will give rise to the same results, so far as they can, after gastro-enterostomy has been performed. For want of being cautioned about this patients are sometimes disappointed with the results of gastro-entero stomy. They think that the operation will cure the condition which gave rise to the stenosis as thoroughly as it cures the stenosis itself. I have known several instances in which patients have come back some months after the operation, declaring in spite of their greatly improved appearance and strength, that they were as bad as they were before the operation. It is $\mathrm{my}$ invariable rule in such cases to put them to bed, to get the bowels to act thoroughly well, and to restrict them to milk diet for a day or two ; and I have never known a case in which the pain did not disappear immediately and recovery follow at once.

Wimpole-street, W.

\section{A CASE OF ABNORMAL DEVELOPMENT OF THE CESOPHAGUS.}

BY J. E. SPICER, M.A., M.B., B.C. CaNTAB., RESIDENT ACCOUCHEUR, LONDON MOSPITAL, WHITECHAPEL, $\mathrm{E}$

DURING the last 18 months three similar cases of congenital malformation of the cesophagus have been admitted to the London Hospital. The anatomical characteristics of two of them, as well as of previously reported cases, have recently been described by Dr. Arthur Keith and myself. ${ }^{1}$ The following case has occurred since and has not yet been recorded. I am indebted to Mr. Jonathan Hutchinson, jun., for permission to publish it.

The abnormality is identical with that of the other cases and can be seen in the accompanying diagrams. It is due to maldevelopment of the tracheo-œsophageal septum in the anterior part of the primitive œesophagus. As a result the upper part of the csophagus is found to end in a dilated cul de sac, while the lower opens above into the posterior wall of the trachea immediately above the bifurcation. The history of the case is as follows.

The patient, a full-term female child of $7 \frac{1}{2}$ pounds in weight; was admitted to the London Hospital a few hours after birth the subject of imperforate anus. There were no other external abnormalities. The child was operated on but the rectum could not be found. The patient died 22 hours after birth. She was the tenth child ard, with the exception of a short umbilical cord which delayed delivery, the birth was natural. The preceding child was described

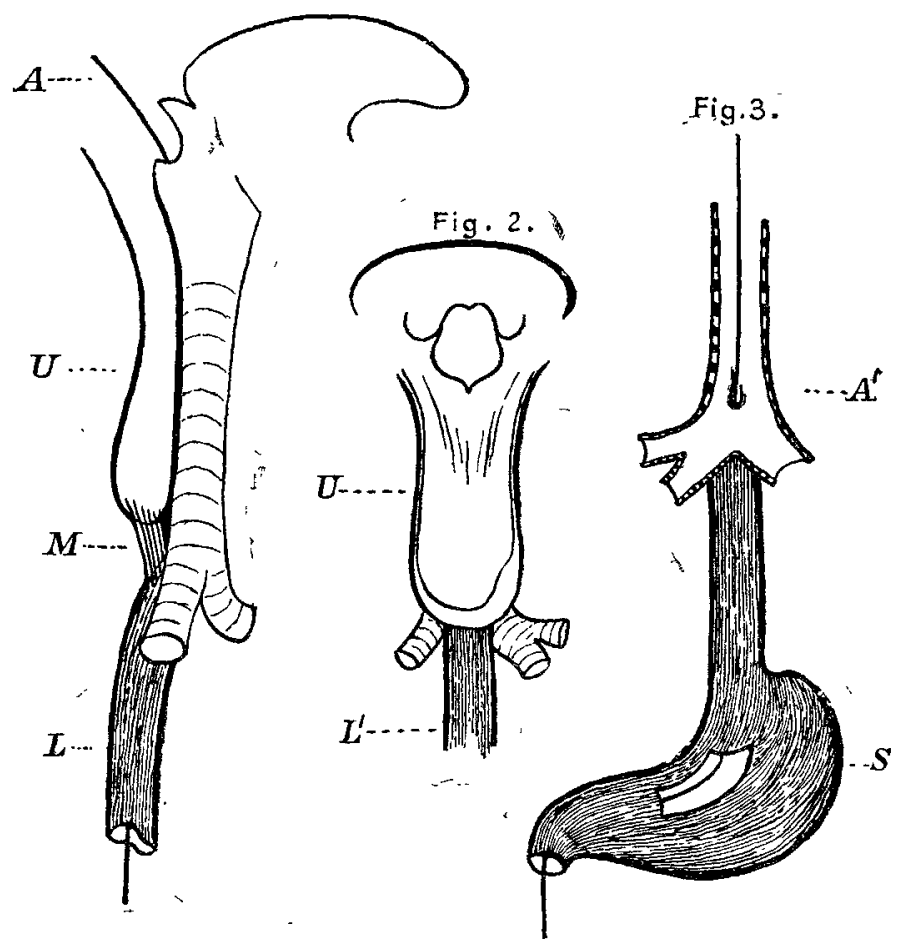

Fig. 1. Side view.-A, Probe inserted in the laryn $\mathrm{x}$ passing through the trachea into the oesophagus. U, Upper end of the cesophargus, ending in cul-de-sac. M, Band of muscle fibres and no communicating passage. L, Lower end of the eesophagus

Fig. 2. Back view.-U, Upper end of the oesophagus, ending in a cul-de sac. $L^{\prime}$, Lower end of the osophagus opening above into the trachea.

Fig. 3. Front view.-A', Opening of the osophagus into the trachea S, Stomach.

by the mother as having been a "blue baby with a hole in its heart" which only lived four hours. Previously to this there had been a miscarriage but the rest of the children are alive and well. There is no apparent abnormality in any of them and the parents are perfectly healthy. One maldevelopment alone is known among the collateral branches 